\title{
DIDELIO MEISTRIŠKUMO RANKININKĖS IZŽAIDE்JOS DARBO INTENSYVUMO KAITA RUNGTYNIAUJANT
}

\author{
Gintarė Onusaitytė, Antanas Skarbalius \\ Lietuvos kūno kultūros akademija, Kaunas, Lietuva
}

\begin{abstract}
Gintarė Onusaitytė. Lietuvos kūno kultūros akademijos studijų programos „Kūno kultūra ir sportas“ magistrantė. Lietuvos moterų rankinio rinktinès kandidatè. Mokslinių tyrimų kryptis — sportininkų rengimo valdymo modeliavimas.
\end{abstract}

\section{SANTRAUKA}

Tyrimo tikslas — nustatyti didelio meistriškumo rankininkès izžaidejos varžybinès veiklos intensyvumo kaita.

Registruota didelio meistriškumo rankininkès ižaidejos širdies veikla — širdies susitraukimu dažnis (广̌SD) — jai rungtyniaujant 2006-2007 metu (per 10 rungtyniu) Lietuvos moteru rankinio čempionate. Širdies susitraukimu dažnis buvo registruojamas 5 sekundžiu intervalais pulso matuokliu „Polar S610i“ (Suomija) nuo pramankštos pradžios iki rungtyniu pabaigos. Siekta nustatyti didelio meistriškumo rankininkès pramankštos, rungtyniu pirmo ir antro kèlinio fizinio krūvio intensyvuma, pramankštos, rungtyniu pirmo ir antro kèlinio fizinio krūvio intensyvumo kaitos priklausomuma nuo rungtyniu baigties.

Visu rungtyniu metu (iskaičiuojant tik pirma ir antrq rungtyniu kèlinius) tiriamosios širdis susitrauke $9354 \pm 884$ kartus. Daugiausia kartu širdis susitraukè antro kèlinio metu, kai rungtynès buvo pralaimètos (5073 \pm 345 kartus). Mažiausiai - per antrq laimètu rungtyniu kèlini (4192 \pm 859 kartus). Didelio meistriškumo rankininkès jžaidejos darbo intensyvumo kaita pramankštos metu - nuo 82 iki $191 \mathrm{tv}$. / min, ir ji buvo mažesnè negu pirmo (nuo 147 iki $193 \mathrm{tv}$. / min) ir antro (nuo $141 \mathrm{iki} 192 \mathrm{tv}$. / min) kèlinio metu. Per pirma ir antra kèlinì krūvio intensyvumo amplitudè buvo beveik tokia pati, tačiau pirmo kèlinio darbo intensyvumas didesnis nei antro. Laimètu rungtyniu pramankštos darbo intensyvumo rodikliai pradejo didèti 21 minutę ir nustojo likus penkioms minutèms iki rungtyniu pabaigos, pralaimètu — 25 minutę, o atsigauti pradèta pirmo kèlinio pirmomis minutèmis. Nepriklausomai nuo rungtyniu baigties — laimètos (nuo $148 \mathrm{iki} 192 \mathrm{tv}$. / min) ar pralaimètos (nuo $147 \mathrm{iki} 193 \mathrm{tv}$. / min) — ŠSD intensyvumo amplitude kito beveik vienodai. Per antra rungtyniu kèlini $\breve{S} S D$ intensyvumas buvo didesnis tada, kai rungtynés pralaimètos (nuo $141 \mathrm{iki} 192 \mathrm{tv}$. min), laimètu (nuo 142 iki $187 \mathrm{tv}$ / min) buvo mažesnis.

Raktažodžiai: moteru rankinis, širdies susitraukimu dažnis, darbo intensyvumas.

\section{IVADAS}

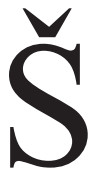
iuolaikinis moterų rankinis dinamiškas (Grunanger, Konig, 2005), iš žaidèjų reikalauja didelių fizinių pastangų ir išskirtinio parengtumo (Macovei, 2004; Mocsai, 2002). Rungtyniaudamos rankininkès atlieka mažos trukmès didžiausių pastangų veiksmus (šuolius, greitèjimus keičiant judejjimo kryptị ir gausybę iqvairių technikos veiksmu, kurie, atsižvelgiant i taktikos situacijas, reikalauja didelių psichinių pastangų) (Taborsky, 2001). Kartu atliekami ir mažesnio intensyvumo vidutinès trukmès veiksmai (keli greitèjimai kontratakuojant ir ginantis nuo varžovų kontratakų). Rankininkès per rungtynių pauzes turi galimybę atsigauti, tačiau norint visų rungtynių 
metu išlaikyti didelę rungtyniavimo spartą būtinas geras aerobinis organizmo parengtumas (Loftin et al., 1996; Cardinale, Manzi, 2002).

Sportininku parengtumą lemia tinkama rengimo programa (Banister et al., 1999; Mester, Perl, 2000; Busso, 2003). Nors žaidimo situacijų perkèlimas i pratybas rengiant komandą taikomas jau daugiau kaip du dešimtmečius, pastaruoju metu padidejjus rungtynių skaičiui vis aktualesnis žaidèjų integralusis rengimas modeliuojant specifinę varžybinę veiklą (Bangsbo, 1994; Reilly, 1993). Varžybinès veiklos tyrimai nustatant sportininko veiklos modelines charakteristikas leidžia optimizuoti rengimo programas ir kryptingai valdyti sportininkų rengimą (Mester, 1993; Reilly, 1993). Ypač reikšmingi ir informatyvūs organizmo fiziologinès veiklos rodikliai (Bavios et al., 2006; Drust et al., 2007).

Rankininkų varžybinè veikla tiriama nuolat, tačiau daugiausia analizuojama rankinio veiksmų struktūra (Czerwinski, 1996; Taborsky, 2001; Mocsai, 2002; Polany, 2006). Rusų mokslininkai V. J. Ignatjeva ir J. M. Portnovas (Игнатьева, Портнов, 1997) nustate, kad rankininku širdis per rungtynes vidutiniškai susitraukia nuo 162 iki 180 tv. / min, J. Alexander ir L. Boreskie (1989) nuo 149 iki 164 tv. / min. Vèliau S. Lupo ir D. Seriacopi (1996) teige, kad rungtynių metu ŠSD svyruoja nuo 140 iki 200 tv. / min. Per rungtynes rankininku širdis susitraukia $9800-10800$ kartu (Игнатьева, Портнов, 1997). Rungtyniu metu ŠSD kaita gana îvairi ir priklauso nuo žaidejjo meistriškumo bei rungtynių pobūdžio.

Šiuolaikiniam rankiniui greitėjant, svarbu nustatyti rankininkų organizmo fiziologinius poreikius, kuriuos geriausiai rodo širdies veikla. Tiek ŠSD kaita rungtyniavimo metu, tiek ŠSD absoliučios reikšmės leistų ivvertinti ir nustatyti rankininku varžybinès veiklos intensyvumo zonas. Be to, ne mažiau svarbu nustatyti ir atskirų žaidimo pozicijų žaidejjų veiklos intensyvumo ribas. Literatūros šaltiniuose nepavyko rasti didelio meistriškumo moteru rankininkių varžybinès veiklos intensyvumą apibūdinančių rodiklių.

Tyrimo tikslas - nustatyti didelio meistriškumo rankininkès įžaidèjos varžybinès veiklos intensyvumo kaita.

\section{Uždaviniai:}

1. Nustatyti didelio meistriškumo rankininkès fizinio krūvio intensyvumą pramankštos, rungtynių pirmo ir antro kélinio metu.

2. Išsiaiškinti, kaip didelio meistriškumo rankininkès pramankštos, rungtyniu pirmo ir antro kèlinio fizinio krūvio intensyvumo kaita priklauso nuo rungtynių baigties.

Tyrimo objektas - rankininkių rungtynių fizinio krūvio intensyvumas.

\section{TYRIMO METODIKA IR ORGANIZAVIMAS}

\section{Tyrimo metodai:}

1. Mokslinè literatūros šaltinių analizè.

2. Pulsometrija.

3. Statistinè duomenų analizè. Išanalizavus tyrimo duomenis apskaičiuotas aritmetinis vidurkis $(\overline{\mathrm{x}})$, standartinis nuokrypis (sd).

Tyrimo organizavimas. Per 2006-2007 metu Lietuvos moterų rankinio čempionato 10 rungtynių buvo registruojamas ižaidejos, rungtyniavusios visą rungtyniu laika, širdies susitraukimų dažnis. ŠSD registruotas nuo pramankštos pradžios iki rungtynių pabaigos, 5 sekundžių intervalais registruojant pulso matuokliu „Polar S610i“ (Suomija). Paskui duomenys perkelti i kompiuteri ir taikant „Polar Precision Performance SW“ bei „Microsoft Excel" programą apskaičiuota ŠSD vidutinė reikšmė per kiekvieną minutę, norint ịvertinti rankininkès 60 minučiu rungtynių veiklos intensyvumą.

\section{REZULTATAI}

Per pirmą rungtynių kèlinį rankininkès vidutinis ŠSD sieké $180 \pm 4$ tv. / min (1 pav.). Pramankštos metu vidutinis ŠSD buvo $149 \pm 14 \mathrm{tv}$. / min 31 tv. / min mažesnis nei per pirmą kèlini. Antro kèlinio metu ŠSD vidutinis siekè $176 \pm 3$ tv. / min vidutiniškai 4 tv. / min mažesnis nei per pirmą kèlinį. Pramankštos metu vidutinis ŠSD buvo mažesnis nei per pirmą ir antrą rungtynių kélini.

Pramankštos intensyvumas pirmą minutę $111 \pm 27$ tv. / min (1 pav.), šešta — padidejo iki $146 \pm 17$ tv. / min. Atliekant raumenu tempimo pratimus (7-11 min), vidutiniškas ŠSD intensyvumas sumažèjo iki $137 \pm 4 \mathrm{tv}$. / min, o nuo 11 minutès - tolygiai didejo ir pasiekè $150 \mathrm{tv}$. / min. Vèliau nuo 16 iki 20 minutès ŠSD stabilizavosi ir buvo lygus $158 \pm 2 \mathrm{tv}$. / min. Didžiausias ŠSD $(165 \pm 10$ tv. / min) pasiektas 21 minutę. Likusi pramankštos laiką, kai atliekami varžybinei veiklai artimi pratimai (22-31 min), ŠSD kito nuo 157 iki 164 tv. / min.

Visu rungtynių metu (iskaičiuojant tik pirmo ir antro kèlinio laika) širdis susitraukè $9354 \pm 884$ kartus. Daugiausia širdis susitraukinejjo antro kèlinio metu, kai rungtynès buvo pralaimetos 
1 pav. Didelio meistriškumo rankininkès ižaidèjos širdies susitraukimų dažnio (ŠSD) kaita pramankštos, rungtynių 1-o ir 2-o kèlinio metu ( $\overline{\mathbf{X}} \pm \mathrm{SD})$
2 pav. Didelio meistriškumo rankininkès ¡žaidèjos bendro širdies susitraukimų skaičiaus pramankštos, 10 minučiu pertraukos tarp kẻlinių, rungtynių 1-o ir 2-o kẻlinio metu priklausomumas nuo rungtyniu baigties ( $\overline{\mathbf{X}} \pm$ SD)
3 pav. Didelio meistriškumo rankininkès į̌zaidèjos širdies susitraukimų dažnio (ŠSD) kaitos rungtynių 1-o ir 2-o kèlinio metu priklausomumas nuo rungtynių baigties $(\overline{\mathbf{X}} \pm$ SD)
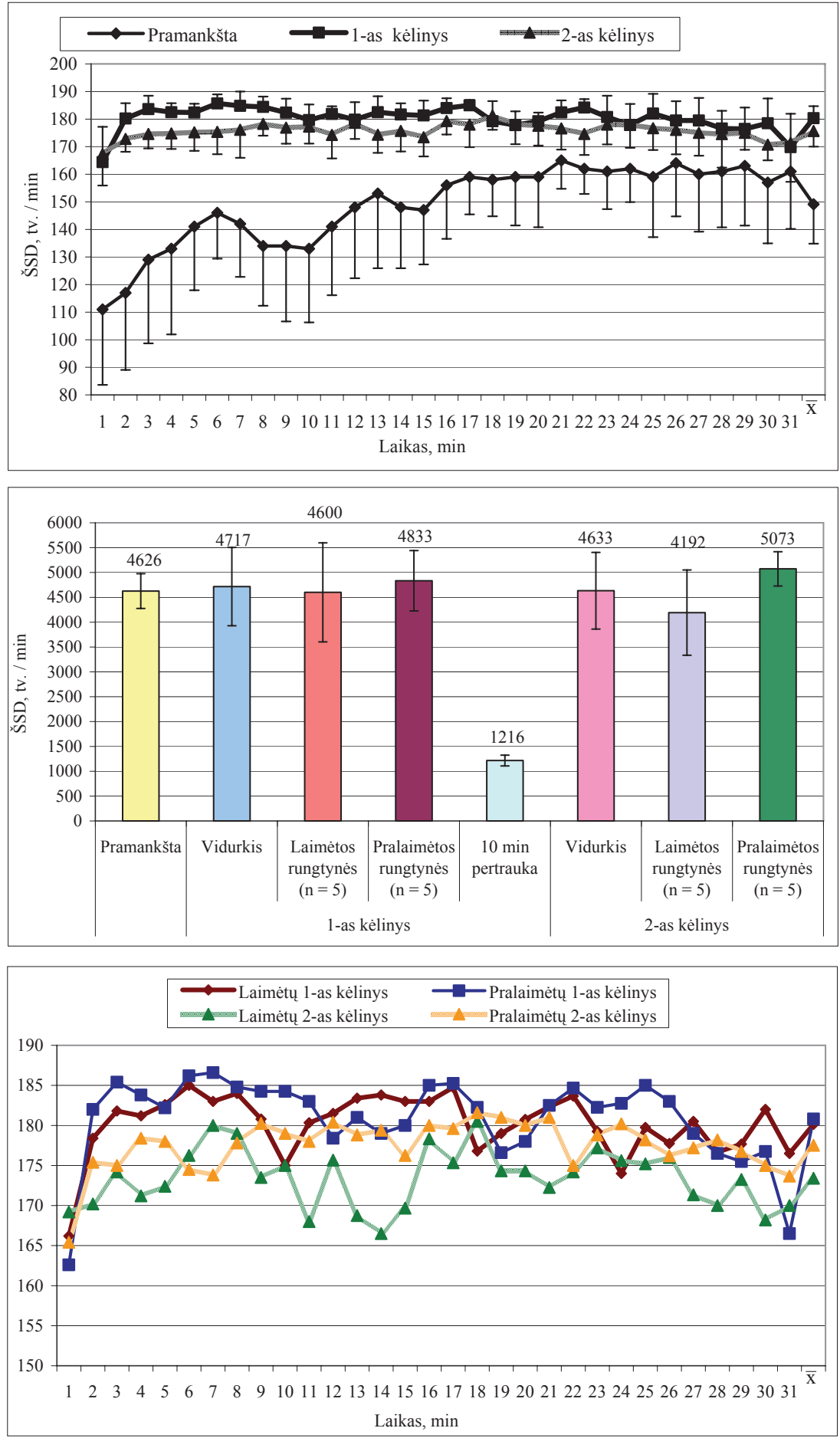

(5073 \pm 345 kartus) (2 pav.), mažiausiai - per antrą laimètų rungtynių kèlini (4192 \pm 859 kartus).

Per pirmą kèlini, kai rungtynès buvo pralaimètos, širdis susitraukinejjo $4833 \pm 608$ kartus, kai laimètos — vidutiniškai 233 kartus mažiau $(4600 \pm 997)$. Panaši širdies veikla nustatyta ir visų rungtyniu metu - didesnis ŠSD tvinksniu skaičius pastebètas per pralaimètas rungtynes $(9906 \pm 483)$ nei per laimètas $(8792 \pm 903)$.

Intensyviausiai rankininkès širdis dirbo pirmo kèlinio metu ir nepriklausomai nuo rungtyniu baigties kito vienodai: per pirmą laimètų rungtynių kèlini ŠSD kito nuo 148 iki 192 tv. / min, per pirmą pralaimètu — nuo 143 iki 193 tv. / min (3 pav.).

Per antrą pralaimètų rungtyniu kèlini širdies veikla buvo penkiais tvinksniais intensyvesnè (141 iki 192 tv. / min) nei laimètuc, tačiau kaita beveik vienoda - atitinkamai nuo 141 iki 192 tv. / min ir nuo $142 \mathrm{iki} 187 \mathrm{tv}$. / min.

Pramankštos metu ŠSD prieš laimètas ar pralaimètas rungtynes kito skirtingai (4 pav.). Kai 


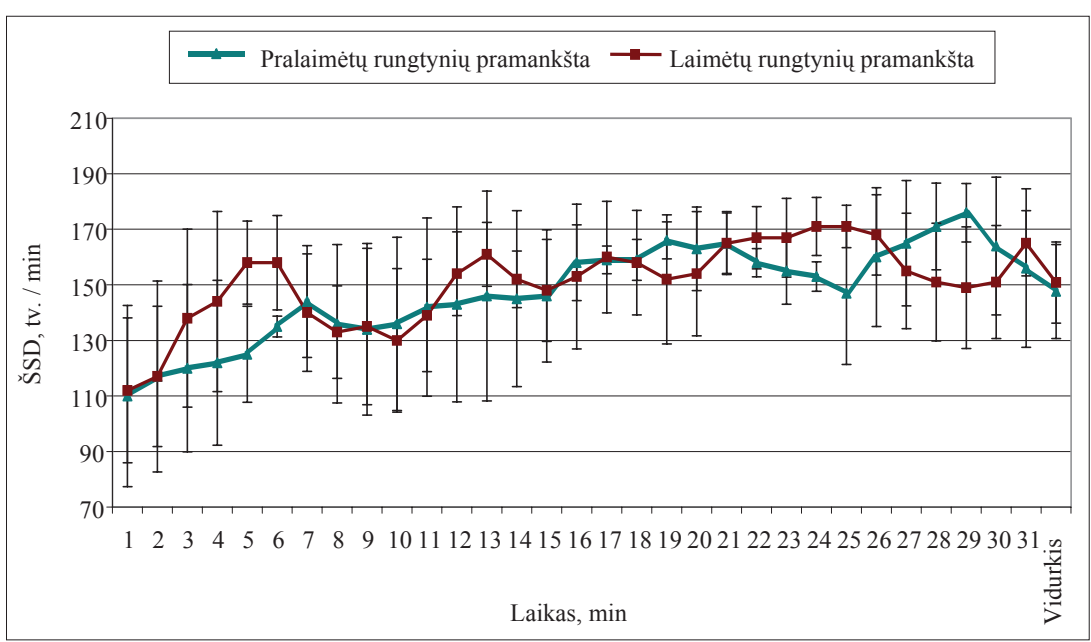

4 pav. Didelio meistriškumo rankininkès ižaidèjos širdies susitraukimų dažnio (ŠSD) kaitos pramankštos metu priklausomumas nuo rungtynių baigties $(\overline{\mathbf{X}} \pm \mathrm{SD})$

rungtynès buvo pralaimètos, pramankštos metu ŠSD intensyvumas kito nuo 82 iki $191 \mathrm{tv}$. / min, kai laimètos — nuo $96 \mathrm{iki} 185$ tv. / min. Kai rungtynès buvo pralaimetos, ŠSD visą pramankštos laiką kito tolygiai ir didžiausias pasiektas pramankštos pabaigoje (29 minutę). Kai rungtynès buvo laimètos, pramankštos ŠSD kreiveje išskirtinos keturios viršūnès: $5-6$ min (158 tv. / min), $13 \mathrm{~min}(161 \mathrm{tv} . / \mathrm{min}), 17 \mathrm{~min}(160 \mathrm{tv} . / \mathrm{min})$ ir 24-25 min (171 tv. / min). Didžiausias ŠSD (171 tv. / min) pasiektas 24-ą ir 25-ą min, t. y. iki rungtynių pabaigos likus penkioms minutèms.

\section{REZULTATŲ APTARIMAS}

J. Alexander ir L. Boreskie (1989) teigia, kad širdies veiklos intensyvumas rungtynių metu yra didesnis negu 149 tv. / min. Vèliau S. Lupo ir D. Seriacopi (1996) nustate didesnio intensyvumo širdies veiklą, siekiančią 190 (tirta 1996 m.) ir net 200 tv. / min (tirta 1998 m.) reikšmę, tačiau abiem atvejais pažymėtiną nuolatinę ŠSD kaitą - 60 tv. / min (tarp didžiausios ir mažiausios reikšmès). Tirtos rankininkès ižaidèjos pirmo ir antro kèlinio metu širdies veiklos intensyvumo kaitos rodikliai sutampa su S. Lupo ir D. Seriacopi (1996) gautaisiais, tačiau nustatyta skirtinga kaita: vidutiniškai ŠSD svyravo labai mažai tiek pirmo $( \pm 4)$, tiek antro kèlinio $( \pm 3)$ metu. Per pastaruosius 10 metų rankinis pasidarè labai dinamiškas - imetama daugiau įvarčių, didejja kontratakomis pelnomų ịvarčių skaičius (Skarbalius, 2006), todèl tikètina, kad ir širdies veikla visu rungtynių metu yra intensyvesnè.

Didelio meistriškumo Lietuvos rankininkès įžaidèjos širdis per rungtynes susitraukinèjo vidutiniškai $9354 \pm 884$ kartų. V. J. Ignatjeva ir J. M. Portnovas (1997) nustatė didesni ŠSD tvinksnių skaičiu per rungtynes (nuo 9800 iki 10800), tačiau nenurodo, ar buvo įskaičiuota širdies veikla per 10 minučių pertrauką tarp kèlinių. Tirtos rankininkès ižzaidejos širdies tvinksnių (be ŠSD per pertrauką tarp kèlinių) minimalios reikšmès rodiklis (8276) 1000 tvinksnių mažesnis negu nustatytas minètų tyrèjų, tačiau atitinka (10906) didžiausią reikšmę (10800).

Didelio meistriškumo Lietuvos rankininkès ¡žaidejjos ŠSD intensyvumo kaitos ribos rungtynių metu atitinka pateiktas dar prieš dvidešimt metu (Alexander, Boreskie, 1989), tokios pačios buvo ir prieš dešimti metų (Lup, Seriacopi, 1996), tačiau nustatyta kaitos amplitudè kur kas mažesnè $( \pm 3,5 \mathrm{tv} . / \mathrm{min})$ nei minètų tyrèjų ( $\pm 60 \mathrm{tv}$. / min). Vadinasi, reikètų manyti, kad šiuolaikinis rankinis reikalauja vienodų didelių pastangų visų rungtynių metu. Vieni tyrejjai tyrè tik ŠSD kaitą, kiti - bendrą širdies veiklą, todèl nèra galimybiu tiksliai nustatyti retrospektyvinių rankinio rungtyniu intensyvumo kaitos ypatumų. Rankinio rungtynių intensyvumo kaitos ypatumų analizè sudètinga dar ir dèl to, kad literatūroje neaptinkama širdies veiklos ypatumu priklausomumo nuo rungtyniu baigties duomenų.

Sportinę sėkmę dažnai lemia pramankšta, todèl svarbu nustatyti, ar pramankštos metu ŠSD intensyvumas turètų būti artimas rungtynių metu pasiektam, ar turètu ji viršyti (Beecher, 2007)? Kyla ir kitokio pobūdžio klausimų: kada pradèti intensyvinti pramankštą, kad organizmas spètu atsigauti iki rungtynių pradžios; kiek laiko po pramankštos reikètų skirti organizmui atsigauti? Rankininku pramankšta užima tiek pat laiko, kaip vienas rungtynių kèlinys (30 min), tačiau ŠSD kinta nevienodai. J. Skernevičius (1997) teigia, kad pramankšta galètų tęstis $20-30 \mathrm{~min}$, po jos reikètu ilsètis iki $15-20$ min, nes, pasak 
autoriaus, trumpai ilsintis nespejjama visiškai atsigauti, sukaupti energinių medžiagu, pašalinti suaktyvejjusios medžiagų apykaitos produktų, o pramankštos trukmè labai priklauso nuo varžybinès veiklos specifikos. Visgi rankininkai tokios metodikos niekada netaiko - jiems po pramankštos poilsiui lieka maždaug 5 minutès (Czerwinski, 1996). Prieš visas rungtynes tiriama rankininkè po pramankštos ilsejjosi penkias minutes, per kurias turejo pasikeisti aprangą ir buvo pristatoma. Kai pramankštos pabaiga buvo suintensyvinta — rungtynès pralaimètos, kitu atveju, kai penkias minutes mankštinantis intensyvumas buvo mažinamas, rungtynès laimètos. Galima teigti, kad pastarasis pramankštos modelis priimtinesnis, tačiau tai tik prielaidos - dèsningumus patvirtinti gali tolesni tyrimai.

Tiriamosios širdies veikla per pralaimètas rungtynes buvo intensyvesnè negu per laimètas. Tai galèjo lemti varžovių meistriškumas, nes penkerios rungtynès buvo žaistos su aukštesnę vietą turnyrinejje lentelejje užimančiomis komandomis (trys iš penkių rungtynių žaistos finaliniame etape) ir visus penkis kartus pralaimèta. Galima manyti, kad ŠSD intensyvumas priklauso nuo rungtyniu rango ir atsakomybès (Fernandez et al., 2006), kuri dèl psichinès itampos galètų turèti didesni poveiki širdies veiklai nei atliekamų veiksmų dydis.

Atlikti tyrimai skatina nustatyti pramankštos intensyvumo, jos kaitos ir rungtynių veiksmingos pradžios bei rungtynių sèkmingos pradžios, širdies veiklos intensyvumo, jos kaitos ir rungtyniu sẻkmès sąsajas.

\section{IŠVADOS}

1. Didelio meistriškumo rankininkès įžaidejos intensyviausia širdies veikla nustatyta per pirmą rungtyniu kèlini ( $180 \pm 4 \mathrm{tv}$. / $\mathrm{min}$; iš viso $4717 \pm 788)$, nedaug mažesnè $(p>0,05)-$ per antrą (176 \pm 3 tv. / min; $4633 \pm 772)$, mažiausia - pramankštos metu $(149 \pm 14 \mathrm{tv}$. / min; $4626 \pm 350)$.

2. Nedidelè širdies intensyvumo kaitos amplitudè $( \pm 3,5)$ abiejų kèlinių metu rodo, kad šiuolaikinis rankinis yra dinamiškas ir reikalauja atitinkamo rankininkių fizinio parengtumo.

3. Būtini tolesni tyrimai, patvirtinantys pramankštos pabaigoje mažinamo intensyvumo ir rungtynių baigties sąsajas.

\section{LITERATŪRA}

Alexander, J., Boreskie, L. (1989). An analysis of fitness and time-motion characteristics of handball. American Journal of Sports Medicine, 17 (1), 76-82.

Bangsbo, J. (1994). Fitness Training in Football - a Scientific Approach. Copenhagen: August Krogh Institute, University of Copenhagen.

Banister, W., Carter, B., Zarkadas, C. (1999). Training theory and taper: Validation in triathlon athletes. Journal of Applied Physiology, 79 (2), 182-191.

Bayios., A., Bergeles, K., Apostolidis, G., Noutsos, S., Koskolou, D. (2006). Anthropometric, body composition and somatotype differences of Greek elite female basketball, volleyball and handball players. Journal of Sports Medicine and Physical Fitness, 46 (2), 27-180.

Beecher, J. (2007). Raise the Heart Rate and Stretch Muscles Before Exercise [žiūrèta 2007-10-22]. Prieiga internetu: <http://fitness.suite101.com/article.cfm/ the_warm_up_a_workout_essential $>$

Busso, T. (2003). Variable dose - response relationship between exercise training and performance. Medicine and Science in Sports and Exercise, 35 (7), 1188-1195.

Cardinale, M., Manzi, V. (2002). Special conditioning in Team Handball: Physiological demands of game-like drills [žiūrèta 2007-10-22]. Prieiga internetu: http://cis.squirming.net $/$ article $/$ index $/$ php? id $=361 \&$ style $=$ printable $\% 20$ $-\% 2020 \mathrm{k} \% 20$ -

Czerwinski, J. (1996). Charakterystyka gry w pilke reczna.
Gdansk: Akademia Wychowania Fizycznago w Gdansku. Drust, B., Atkinson, G., Reilly, T. (2007\}. Future perspectives in the evaluation of the physiological demands of soccer. Sports Medicine, 37 (9), 783 -805.

Fernandez, J., Mendez-Villanueva, A., Pluim, B. M. (2006). Intensity of tennis match play. British Journal of Sports Medicine, 40, 387-391.

Grunanger, H., Konig, H. (2005). $5^{\text {th }}$ European championship for women's 17 Vienna 2005 qualitative trend analysis [žiūrèta 2007-09-23]. Prieiga internetu: $<$ http://home.eurohandball.com/ehf_files/specificHBI/ECh_Analyses/2005/ AUT/4/Trend\%20Analyse.pdf $>$

Loftin, M., Anderson, P., Lytton, P., Pittman, P., Warren, B. (1996). Heart rate response during handball singles match-play and selected physical fitness components of experienced male handball players. Journal of Sports Medicine and Physical Fitness, 36 (2), 95-99.

Lupo, S., Seriacopi, D. (1996). Analisi dell'allenamento e della gara. Handball study, 1, 21-35.

Macovei, B. (2004). $6^{\text {th }}$ European championship for women's Hungary 2004 qualitative trend analysis [žiūrèta 2007-09-23]. Prieiga internetu: <http://home.eurohandball. com/ehf_files/specificHBI/ECh_Analyses/2004/HUN/4/ Trend\%20Analysis\%20Macovei_070305m.pdf>

Mester, J. (1993). Elite Sport: The Present Level of Scientific Reserch - Legitimation, Designs and Methods. Sport Sciences in Europe 1993. Current and Future Perspectives 
(254-259). Meyer \& Meyer Verlag.

Mester, J., Perl, J. (2000). Grenzen der Anpassung- und Leistungsfähigkeit aus systemischer Sicht- Zeitreihenanalyse und ein informatisches Metamodell zur Untersuchung physiologischer Adaptionsprozesse. Leistungssport, 30 (1), 43-51.

Mocsai, L. (2002). Analysing and Evaluating the $5^{\text {th }}$ Men's European Handball Championship. Handball. Periodical for Coaches, Referees and Lectures, 3-12.

Pollany, W. (2006). $7^{\text {th }}$ European championship for men Switzerland 2006 qualitative trend analysis [žiūrèta 200703-18]. Prieiga internetu: $<$ http://activities.eurohandball.co $\mathrm{m} /$ ? mode $=104 \& \mathrm{ctrl}=11 \&$ id $1=457 \&$ id $2=458 \& i d 3=472>$
Reilly, T. (1993). Fundamental and applied research in team sports. Sports Sciences in Europe 1993. Current and Future Perspectives (pp. 260-270). Meyer \& Meyer Verlag.

Skarbalius, A. (2006). Šiuolaikinis vyru rankinis: varžybines veiklos modeliai. Kaunas: LKKA.

Skernevičius, J. (1997). Sporto treniruotès fiziologija. Vilnius: LTOK.

Taborsky, F. (2001). Game performance in Handball. Periodical for Coaches, Referees and Lectures, 2 (12), $23-26$

Игнатьева, В. Я., Портнов, Ю. М. (1997). Гандбол. Москва: Физкультура, образование и наука.

\title{
ALTERATION OF HEART RATE INTENSITY DURING MATCH OF HIGH-PEAK PERFORMANCE PLAYMAKER IN HANDBALL
}

\author{
Gintarė Onusaitytė, Antanas Skarbalius \\ Lithuanian Academy of Physical Education, Kaunas, Lithuania
}

\begin{abstract}
The aim of the study was to determine the alteration of heart rate intensity during the match of high-peak performance playmaker in handball. The object of the study was the intensity of female handball player's physical loads during the match.

During ten matches of the Lithuanian female championship in 2006-2007, the heart rate of the playmaker was recorded. The heart rate was recorded in a period of 5 seconds by a pulse meter "Polar S610i" (Finland) and analyzed further with Microsoft Excel program. The data of the heart rate performance were registered starting with the warm-up till the end of the match and after it. The objectives of the study were to determine the heart rate intensity during the warm up, the first and the second half of the game of a high-peak playmaker in handball and to compare the intensity between warm up, the first and the second half-times to the result of the match.

The total heart rate of the high-peak performance playmaker averaged $9354 \pm 884$ beats during the match. The minimal amount heart rate during the match of the female playmaker was 1000 beats lower (8276), but it was adequate to the highest ones (10906). The intensity change limits of the heart rate of the high-peak playmaker were similar to those determined twenty years ago and remained like that for over ten years (in 1996), but the change amplitude decreased dramatically from \pm 60 beats $/ \mathrm{min}^{-1}$, as were determined by the previously mentioned research, to the \pm 3.5 beats $/ \mathrm{min}^{-1}$ - as this study showed. The heart rate of the playmaker in handball was the highest during the first half (from 147 to 193 beats / $\mathrm{min}^{-1}$ ), lower during the second half of the game (from 141 to 192 beats $/ \mathrm{min}^{-1}$ ) and the lowest during the warm-up (from 82 to 191 beats $/ \mathrm{min}^{-1}$ ). The findings suggest that the physiological demands of playmaker during the whole match are highly emphasized because of the very low variation of the heart rate standard deviation $( \pm 3.5)$. When intensity of loads was decreased at the end of the warming-up, the matches were successful. Further research is needed in order to study this phenomenon.
\end{abstract}

Keywords: female handball, heart rate, alteration of heart rate intensity.

Gauta 2008 m. sausio 24 d.

Received on January 24, 2008

Priimta 2008 m. gegužès 13 d

Accepted on May 13, 2008
Antanas Skarbalius

Lietuvos kūno kultūros akademija

(Lithuanian Academy of Physical Education)

Sporto g. 6, LT-44221 Kaunas

Lietuva (Lithuania)

Tel +370 37209144

E-mail a.skarbalius@1kka.1t 